\title{
Isolation of Ef silicatein and Ef lectin as Molecular Markers for Sclerocytes and Cells Involved in Innate Immunity in the Freshwater Sponge Ephydatia fluviatilis
}

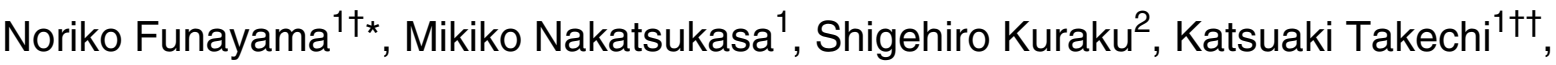 \\ Mikako Dohi ${ }^{1}$, Naoyuki Iwabe ${ }^{3}$, Takashi Miyata ${ }^{3}$ and Kiyokazu Agata ${ }^{1 \dagger}$ \\ ${ }^{1}$ Group for Evolutionary Regeneration Biology, Center for Developmental Biology, RIKEN Kobe, \\ 2-2-3 Minatojima-Minami, Chuo-ku, Kobe 650-0047, Japan \\ ${ }^{2}$ Laboratory for Evolutionary Morphology, Center for Developmental Biology, RIKEN Kobe, \\ 2-2-3 Minatojima-Minami, Chuo-ku, Kobe 650-0047, Japan \\ ${ }^{3}$ Department of Biophysics, Graduate School of Science, Kyoto University \\ Kitashirakawa-Oiwake, Sakyo-ku, Kyoto 606-8502, Japan
}

\begin{abstract}
Sponges (phylum Porifera) have remarkable regenerative and reconstitutive abilities and represent evolutionarily the oldest metazoans. To investigate sponge stem cell differentiation, we have focused on the asexual reproductive system in the freshwater sponge Ephydatia fluviatilis. During germination, thousands of stem cells proliferate and differentiate to form a fully functional sponge. As an initial step of our investigation of stem cell (archeocyte) differentiation, we isolated molecular markers for two differentiated cell types: spicule-making sclerocyte cells, and cells involved in innate immunity. Sclerocyte lineage-specific Ef silicatein shares $45 \%$ to $62 \%$ identity with other sponge silicateins. As in situ hybridization of Ef silicatein specifically detects archeocytes possibly committed to sclerocytes, as well as sclerocytes with an immature or mature spicule, therefore covering all the developmental stages, we conclude that Ef silicatein is a suitable sclerocyte lineage marker. Ef lectin, a marker for the cell type involved in innate immunity, shares $59 \%$ to $65 \%$ identity with the marine sponge Suberites domuncula galactose-binding protein (Sd GBP) and horseshoe crab Tachypleus tridentatus tachylectin1/lectinL6. Since Sd GBP and tachylectin1 are known to bind to bacterial lipopolysaccharides and inhibit the growth of bacteria, Ef lectin may have a similar function and be expressed in a specialized type of cell involved in defense against invading bacteria. Ef lectin mRNA and protein are not expressed in early stages of development, but are detected in late stages. Therefore, Ef lectin may be specifically expressed in differentiating and/or differentiated cells. We suggest Ef lectin as a marker for cells that assume innate immunity in freshwater sponges.
\end{abstract}

Keywords: Porifera, sclerocyte, silicatein, tachylectin, innate immunity

\section{INTRODUCTION}

Sponges (phylum Porifera) represent evolutionarily the oldest metazoans. Sponges have remarkable reconstitutive and regenerative abilities. The stem cells, known as archeo-

\footnotetext{
* Corresponding author. Phone: +81-75-753-3649;

Fax : +81-75-753-4200;

E-mail: funayama@cdb.riken.jp

${ }^{\dagger}$ Present address: Laboratory for Molecular Developmental Biology, Department of Biophysics, Graduate School of Science, Kyoto University, Kitashirakawa-Oiwake, Sakyo-ku, Kyoto 6068502, Japan

${ }^{+\dagger}$ Present address: Faculty of Science, Kumamoto University, 2-391 Kurokami, Kumamoto 860-8555, Japan
}

cytes, play a significant role in the reconstitution of the dissociated sponge (De Sutter and Van de Vyver, 1977). However, previous investigations have been restricted to morphological studies, and our current understanding of the molecular mechanisms and regulation of sponge stem cell differentiation remains poor.

The body of the sponge is constructed by epithelial cells and by tissues, known as the mesohyle, bounded by and lying internal to the epithelial cells. Many types of cells migrate within the mesohyle. Cell types of the sponge have mostly been designated by their morphological features. More than 10 types of cells have been reported. These include the archeocyte, the stem cell; the thesocyte, or rest- 
ing state of the archeocyte in the gemmule; the choanocyte, or feeding cell; the exopinacocyte, the outer epithelial cell; the endopinacocyte, the inner epithelial cell; the basopinacocyte, the basal epithelial cell; and the sclerocyte, or spicule-making cell. Additionally, spongocytes, collagenocytes and lophocytes have been described as active in collagen biosynthesis.

To elucidate the mechanisms involved in the regulation of archeocyte differentiation, we have focused on germination, the process by which a new sponge hatches from a gemmule, during asexual reproduction. The freshwater sponge Ephydatia fluviatilis, used in our study, has both sexual and asexual reproductive systems. The advantage in using this species is that it has gemmules throughout the year, and germination can be initiated in vitro at any season. Germination is a highly ordered process that has been extensively studied morphologically, mostly in freshwater sponges (Brien, 1932; Höhr, 1977).

Surrounded by a collagen coat in the gemmule are thousands of yolk-laden cells, the thesocytes (the resting state of archeocytes). As hatching from the gemmule is usually inhibited by inhibitory factors from parental tissue, removal of parental tissue surrounding the gemmule initiates germination. When germination begins, thesocytes undergo mitosis within the gemmule coat and become either archeocytes (nuclei with a large, single nucleolus) or histoblasts (nuclei lacking a nucleolus and with few, if any, platelets) (Simpson, 1984). Histoblasts and archeocytes then migrate out from the gemmule coat. Archeocytes proliferate and differentiate to form a fully functional miniature sponge. Histoblasts become basopinacocytes in the initial stages of germination (Simpson, 1984). However, it is still not clear whether histoblasts directly differentiate from thesocytes, or from archeocytes produced from thesocytes.

During germination, all types of sponge cells are derived from archeocytes directly or indirectly; therefore, we focused on the germination process as a unique system to investigate the regulation of stem cell differentiation in the oldest group of metazoans. We have divided the germination of E. fluviatilis into 6 stages based on our observations and unpublished data of Fujieda and Watanabe (Funayama et al., 2005). E. fluviatilis forms a fully functional sponge from the gemmule within a week. Stage 0 ( 0 days old) is the resting gemmule (Fig. 1A). Stage 1 (2 days old) is when the sponge epithelial envelope is constructed from the first group of cells migrating from the gemmule. Cells also migrate into the inner space of the envelope. Stage 2 (3-4 days old) is when more cells migrate into the epithelial envelope, proliferate, and begin to differentiate into many cell types, such as sclerocytes and choanocytes (Fig 1B,; Funayama et al., 2005). Stage 3 (5 days old) is when the canal system and choanocyte chambers lining along the canal are formed. Stage 4 (6-7 days old) is when the oscule is finally developed and a fully functional sponge is formed (Fig. 1C). In stage 5 (8-12 days old), the sponge maintains and gradually increases the size of its body. In our non-feeding culture system, sponges eventually die around 14 days after the start of germination. Until recently, most research on sponge cell biology had been observational. To further understand archeocyte differentiation, molecular studies are required, and therefore as an initial step we have been working on isolating molecular markers for both archeocytes and differentiated cell types.

In this study we isolated molecular markers for two types of differentiated cells in Ephydatia fluviatilis by BLAST search of our ongoing EST library: Ef silicatein for sclerocytes and Ef lectin for cells which may possibly be involved in defense against bacteria. As the developmental processes of both types of cells can be specifically detected by in situ hybridization using these genes, we conclude that $E f$ silicatein and Ef lectin can be used as cell lineage-specific molecular markers.

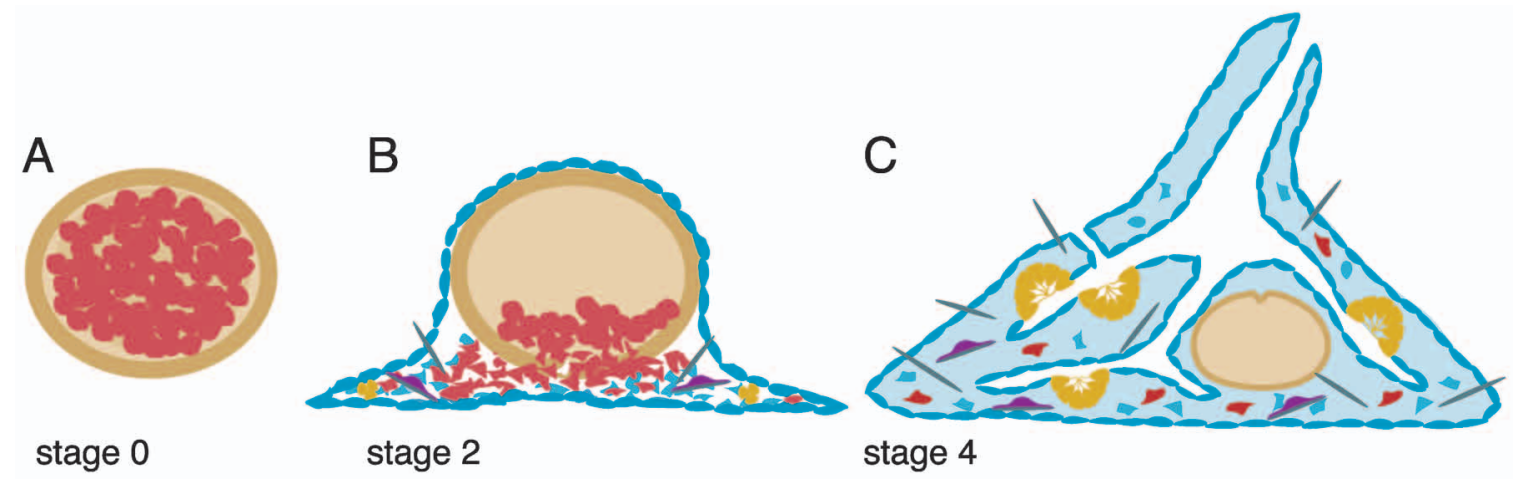

Fig. 1. Schematic drawing of the developmental stages of the germination process we used in this study. (A) Stage 0 (0-day sponge): resting gemmule. (B) Stage 2 (4-day sponge): archeocytes proliferate and begin to differentiate into many cell types after migrating into the space inside the epithelial envelope. (C) Stage 4 (7-day sponge): fully functional sponge with an oscule, the excurrent opening. In stage 5 (10-day sponge), the cellular composition is the same as in stage 4, but the size of the sponge body has increased. Archeocyte (red), pinacocyte (dark blue), differentiated cell (light blue) in mesohyle (the inner space of the sponge body), sclerocyte (purple), choanocyte (yellow), spicule (gray), gemmule shell (light brown). 


\section{MATERIALS AND METHODS}

\section{Biological samples}

Gemmule-bearing sponges, Ephydatia fluviatilis, were collected from the Yokotone River in Ibaraki Prefecture, Japan. Gemmules attached to parental sponge tissue were stored in water in the dark at $4^{\circ} \mathrm{C}$.

\section{Cultivation}

Gemmules were isolated from parental sponge tissue and treated with $1 \% \mathrm{H}_{2} \mathrm{O}_{2}$ to reduce bacterial and fungal contaminants included in the coat. They were subsequently washed 10 times with sterilized water, then stored at $4^{\circ} \mathrm{C}$ until use. Gemmules were moved to sterile mineral medium (M-medium: $1 \mathrm{mM} \mathrm{CaCl}_{2} \cdot \mathrm{H}_{2} \mathrm{O}, 0.5$ $\mathrm{mM} \mathrm{MgSO}{ }_{4} \cdot 7 \mathrm{H}_{2} 0,0.5 \mathrm{mM} \mathrm{NaHCO}, 0.05 \mathrm{mM} \mathrm{KCl}, 0.25 \mathrm{mM}$ $\mathrm{Na}_{2} \mathrm{SiO}_{3} \cdot 9 \mathrm{H}_{2} \mathrm{O}$ ) in sterile dishes and cultured at room temperature. Sponges were not fed during the experiments.

\section{5' RACE}

For amplification of the 5' end of E. fluviatilis Ef silicatein and Ef lectin mRNA, we performed 5' RACE (rapid amplification of cDNA ends) using SMART TM RACE cDNA Amplification Kit (BD Bioscience Clonetech, Franklin Lakes, NJ, USA) according to the manufacturer's instructions. PCR products were electrophoresed on an agarose gel, purified, cloned into pCR 2.1 TOPO vector (Invitrogen, Carlsbad, CA, USA), and sequenced.

\section{Probe preparation}

EST clones Ef_g5w_218G02 (Ef silicatein) and Ef_g5w_225J19 (Ef lectin) were used; these contained $1,077 \mathrm{bp}$ and $860 \mathrm{bp}$ of insert cDNA, respectively, between EcoRI and Xhol restriction sites of pBluescript SK (+) (BD Bioscience Clonetech, Franklin Lakes, NJ, USA). To prepare antisense cRNA probes, Ef_g5w_218G02 was cut with BamHI and Ef_g5w_225J19 was cut with Pstl, and for sense probes both EST clones were cut with Xhol. Digoxygeninlabelled RNA probes were prepared according to the manufacturer's instructions (Roche Diagnostics, Tokyo, Japan).

\section{Whole-mount in situ hybridization}

Sponges were grown on a cover glass, then fixed with $4 \%$ paraformaldehyde (PFA) in 1/4 Holtfreterís solution (1/4HS: 87.5 $\mathrm{mg} \mathrm{NaCl}, 1.25 \mathrm{mg} \mathrm{KCl}, 2.5 \mathrm{mg} \mathrm{CaCl}, 5 \mathrm{mg} \mathrm{NaHCO}$ in $100 \mathrm{ml}$ ) overnight at $4^{\circ} \mathrm{C}$. Whole-mount in situ hybridization was performed as described previously (Funayama et al., 2005).

\section{Molecular phylogenetics}

Sequences that showed significant BLAST (Altschul et al., 1997) homology to Ef lectin were retrieved from the database, and an optimal multiple alignment of these amino acid sequences was constructed using the alignment editor XCED, in which the MAFFT program is implemented (Katoh et al., 2002), together with manual inspection. Using the regions in which the alignment was unambiguous and no gaps existed, molecular phylogenetic trees were inferred by the neighbor-joining method (Saitou and Nei, 1987) using the JTT model in XCED, and by the maximum-likelihood method (Felsenstein, 1981) in PAML (Yang, 1997), with among-site rate heterogeneity taken into account (Yang, 1994) with the shape parameter that maximizes the likelihood of the tree.

\section{Antibodies against Ef lectin}

cDNA encoding 21-160 amino acid residues of Ef lectin was inserted between the Sall and Pstl sites of pQE30 (QIAGEN, Hilden, Germany) to express recombinant Ef lectin. Anti-Ef lectin polyclonal antibodies were raised against the recombinant Ef lectin by MBL (Nagoya, Japan).

\section{Western blot analysis}

Western blot analysis was performed according to Towbin et al. (1979). After SDS-polyacrylamide gel electrophoresis, proteins were transferred onto Clear blot membrane-p (ATTO, Tokyo, Japan). Membranes were blocked with ECL blocking agent (Amersham Biosciences, Piscataway, NJ, USA), then incubated for $1 \mathrm{hr}$ at room temperature with rabbit antisera raised against lectin fusion protein (1:3000). After intense washing with TBST (20 mM Tris base, $137 \mathrm{mM} \mathrm{NaCl}, 0.1 \%$ Tween20, $\mathrm{pH} 7.6$ ), membranes were incubated with anti-rabbit-HRP (1:1500, Amersham Biosciences, Piscataway, NJ, USA). Signals were detected by ECL Plus Western Blotting Detection Reagents (Amersham Biosciences, Piscataway, NJ, USA) and Lumino image analyzer (LAS-1000 mini; FUJIFILM, Tokyo, Japan).

\section{RESULTS}

\section{Isolation of Ephydatia fluviatilis silicatein cDNA}

In this study, we focused on two genes as candidates for differentiated cell type-specific markers. One is silicatein for sclerocytes, the cell type specialized to form the needlelike spicules that support the organism. Siliceous sponges deposit silica on their spicules. Silicatein has been postulated to be the key enzyme for spicule synthesis in the demosponges Tetyea aurentium (Shimizu et al., 1998) and Suberites domuncula (Krasko et al., 2000; Schröder et al., 2003a), and therefore is a good candidate for a sclerocytespecific marker.

The clone Ef_g5w_218G02 was identified in our EST library as having significant homology to silicateins of marine sponges. As the Ef_g5w_218G02 N-terminus of the coding region was lacking, we performed 5' RACE and extended $102 \mathrm{bp}$ to obtain the full coding sequence of silicatein. A 1,179 bp cDNA sequence was obtained that encoding 326 amino acids with high sequence similarity to other known silicateins and $S$. domuncula cathepsin $\mathrm{L}(\mathrm{Sd}$ cathepsin L), as shown in Fig. 2. As the deduced amino acid sequence of Ef_g5w_218G02 plus the 5' RACE sequence had all the characteristics reported for other sponge silicatein as described below, we designated this gene as Ef silicatein. Ef silicatein is about $60 \%$ identical to Sd silicatein, Tetyea aurentium silicatein alpha (Ta silicatein alpha) and Ta silicatein beta. It also shares $45 \%-49 \%$ identiy with Petrosia ficiformis silicatein (Pf silicatein), Sd silicatein beta and Sd cathepsin L. The alignment of sponge silicateins and Sd cathepsin L shows that residues 109-326 of Ef silicatein correspond to the mature enzyme domain of cathepsin $L$. Three amino acids of Ef silicatein, $\mathrm{Ser}^{134}$, $\mathrm{His}^{273}$ and $\mathrm{Asn}^{293}$, correspond to the catalytic triad Cys, His and Asn in cathepsin L. A serine-rich domain which is conserved in silicateins of other species is also present in amino acids 263-270 of Ef silicatein (Krasko et al., 2000).

\section{Ef silicatein expression during germination}

We then analyzed the expression of Ef silicatein during germination. As the sclerocyte is known by microscopic studies to start differentiation in 2-day sponges in a sandwich culture system (Weissenfels and Landschoff, 1977), 


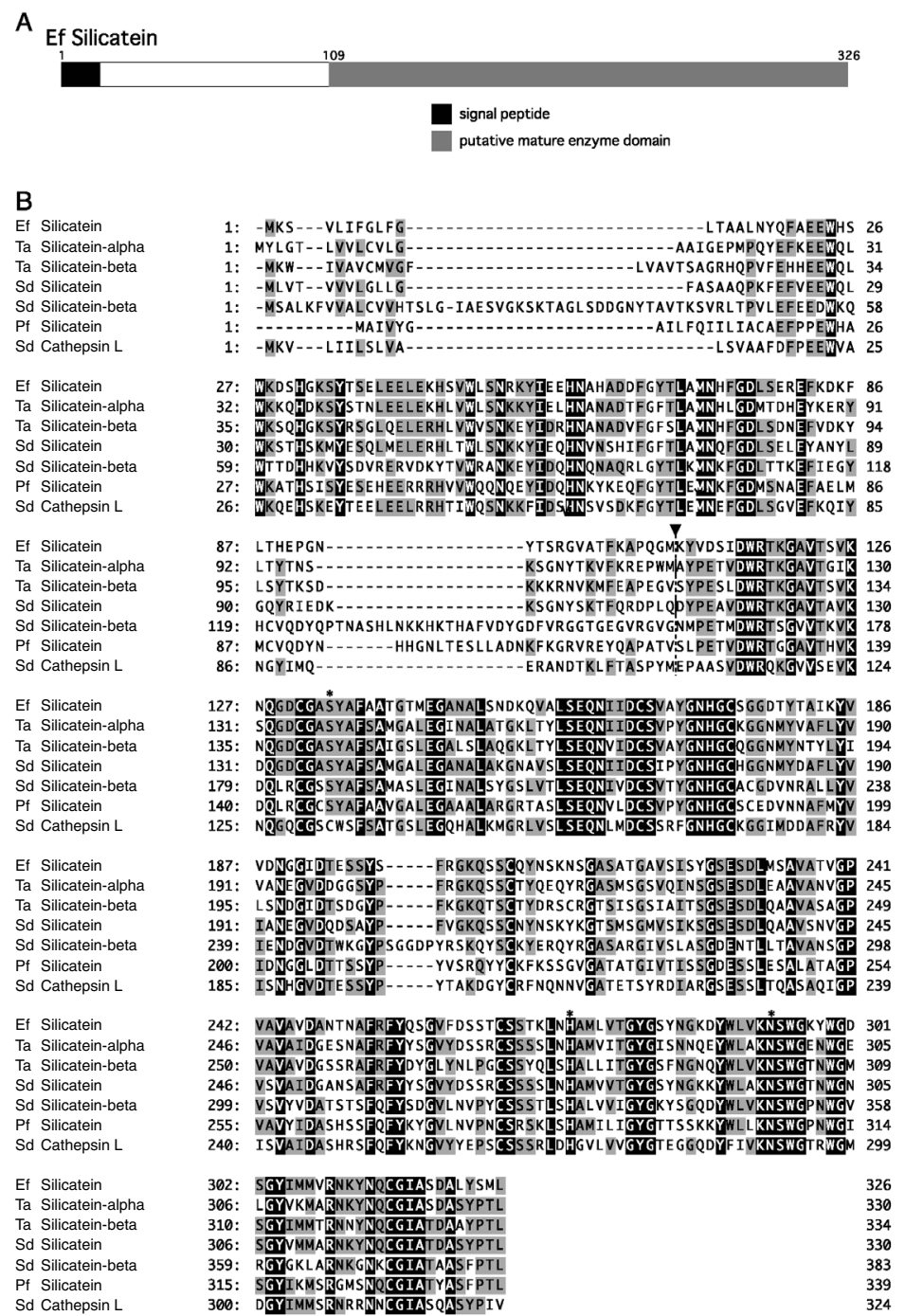

Fig. 2. Amino acid sequence of Ef silicatein. (A) Schematic drawing of the structure of the Ef silicatein protein. (B) Deduced amino acid sequence of Ef silicatein aligned with silicateins of the marine sponges $T$. aurantia (Ta), S. domuncula (Sd) and Petrosia ficiformis (Pf), and $S$. domuncula cathepsin L. Amino acids that match perfectly in all proteins are highlighted in black; amino acids that match more than $51 \%$ are highlighted in gray. Positions of conserved cysteine, histidine and asparagine residues in the catalytic site of cathepsin $L$ are asterisked. The characteristic cleavage sites of Ta Silicatein alpha and Sd silicatien are indicated with black arrowheads and a line. GenBank accession numbers are: Ef silicatein, AB219573; Ta silicatein alpha, AAC23951; Ta silicatein beta, AAF21819; Sd silicatein, AJ272013; Sd silicatein beta, AJ547635; Pf silicatein, AAO23671; Sd cathepsin L, AJ784224.

both differentiating and mature sclerocytes are expected to be seen in stage 2 (4 day) sponges (Figs. 1B, 3A). Although useful for morphological observations by microscopy, the sandwich culture system proved difficult when performing in situ hybridization, as sponges are cultured in a very narrow space (approx. $80 \mu \mathrm{m}$ ), making the changing of reagents difficult. We therefore cultured sponges freely on a cover slip and developed whole-mount in situ hybridization methods for these sponges. In situ hybridization on stage 2 (4-day) sponges with the Ef_g5w_218G02 probe showed Ef silicatein expression in many elongated cells that contained a spicule (Fig. 3B). At higher magnification, Ef silicatein signals were easily detected and photographed (Fig. 3C). Ef silicatein-expressing cells could be divided into three groups by their morphology: round cells (Fig. 3C, insert), cells containing a comparatively short spicule, and cells containing a long spicule (Fig. 3C). A spicule was not detected in the round cells, and as these cells contained a relatively large amount of yolk granules, we speculate that they are archeocytes committed to differentiate into sclerocytes, or sclerocytes in the primary stage of spicule development, with no spicule or a very short one. In the cells with a thin and relatively short spicule, the spicule was not firm, and the ends were flabby, probably because the spicule has little silica deposited and was still soft (Fig. 3C, arrowheads). This type of cell is likely to be a sclerocyte at the stage of developing a spicule. Cells containing a long spicule are likely to be sclerocytes at a late stage of spicule development, as the 

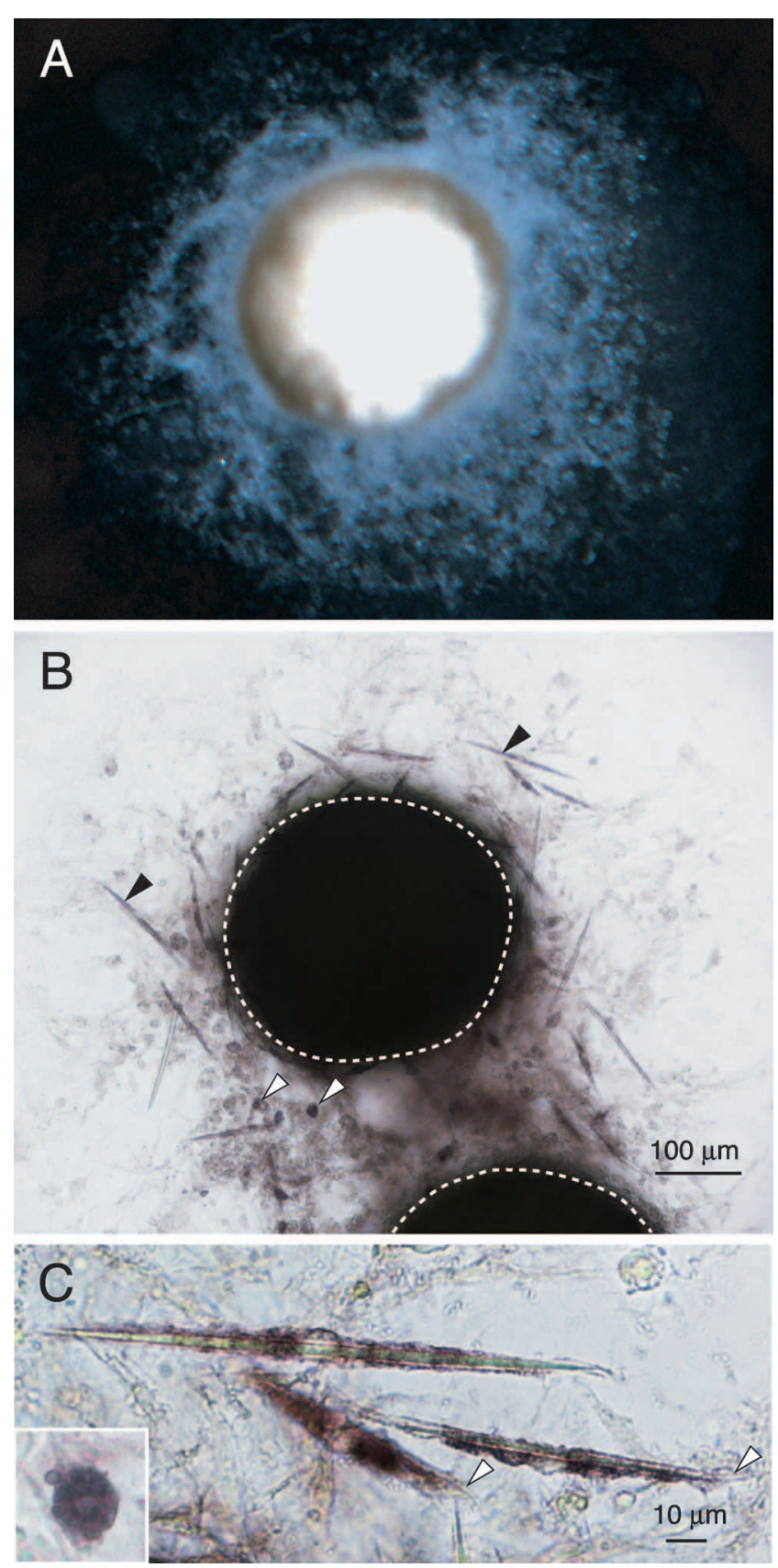

Fig. 3. Ef silicatein expression in the sclerocyte lineage. Wholemount in situ hybridization of Ef silicatein in stage 2. (A) An bright image of a stage 2 sponge. (B) Ef silicatein expression is detected in sclerocytes forming a spicule (black arrowheads), and round cells (white arrowheads). (C) At higher magnification, the developing spicule can be detected inside each elongating sclerocyte. Sclerocytes in the early stage of spicule formation have a short, thin immature spicule. Note that the spicule is slightly bent, indicating that it is still immature with little silica deposited ( $\mathrm{C}$, white arrowheads). A round cell expressing Ef silicatein contains a relatively large amount of yolk granules and is presumably an archeocyte committed to become a sclerocyte ( $\mathrm{C}$, insert).

thickness of the spicule is similar to that of a mature spicule. It is known that the sclerocyte punctures and rounds itself off from the mature spicule in the final stage of development
(Imsiecke and Muller, 1995). From our results, we conclude that Ef silicatein is a suitable molecular marker for cells in the sclerocyte lineage, covering the full range of sclerocyte development.

We found that in taking images of the specimens, illumination from below the sponge was better than illumination from above, probably because light from above reflects diffusely off the shell of the gemmule. However, light from below created a shadow of the gemmule shell (Fig. 3B, circled with white dashed line) and the cells of the middle part of the sponge body that overlapped with the Ef silicatein signal (Fig. 3B).

\section{Isolation of Ephydatia fluviatilis lectin cDNA}

Our next focus was on a specific type of lectin gene as a molecular marker candidate for the cell type specialized in innate immunity. Recently, a tachylectin-related lectin was isolated and analyzed in depth in the marine sponge $S$. domuncula, and was designated as a galactose-binding protein (Sd GBP). Sd GBP binds to lipopolysaccharides (LPS) and inhibits bacterial growth (Schröder et al., 2003b). Furthermore, Sd GBP shares the highest sequence similarity with a lectin from the horseshoe crab Tachypleus tridentatus called tachylectin1, identical to lectinL6, which also binds to LPS and inhibits the growth of Gram-negative bacteria (Schröder et al., 2003b; Saito et al., 1995; Kawabata and Iwanaga, 1999; Shigenaga et al., 1993). We therefore searched our EST library for genes that are highly homologous to Sd GBP and identified the clone Ef_g5w_225J19. We obtained $880 \mathrm{bp}$ of the whole nucleotide sequence of Ef_g5w_225J19, including sequence from 5' RACE. The deduced protein was 242 amino acids long and was designated as Ef lectin, as it has the 6 tachylectin repeats characteristic of tachylectins (Fig. 4A), and shares high identity with Sd GBP (62\%) and T. tridentatus lectinL6 (64\%) and tachylectin1 (59\%) (Fig 3B). Although lectinL6 and tachylectin1 are known to be identical (Kawabata and Iwanaga, 1999), there are some differences between their amino acid sequences, possibly due to the sequence of lectinL6 being determined by peptide sequencing of the purified protein, whereas that of tachylectin 1 was deduced from a cDNA sequence. In addition, Ef lectin shares 35\% identity with Hydractinia echinata tachylectin-related protein precursor (He CTRN) and tachylectin-like protein (He TLP) (Fig. 4B). The predicted signal peptide sequence spans amino acid residues 1-20, and the calculated molecular weight of the mature Ef lectin is about $24 \mathrm{KDa}$. The unrooted tree constructed with Ef lectin- and tachylectin-related proteins shows that Ef lectin is most closely related to Sd GBP and T. tridentatus tachylectin-1/ lectinL6 (Fig. 4C). Hydra tachylectin-like proteins (CTRN and TLP) formed a separate group. Tachylectins are known to act extracellularly (Kawabata and Iwanaga, 1999). Slime mold tectonins are located on the exterior surface of the plasma membrane and have been proposed to function in phagocytosis of bacteria (Huh et al., 1998). 
A
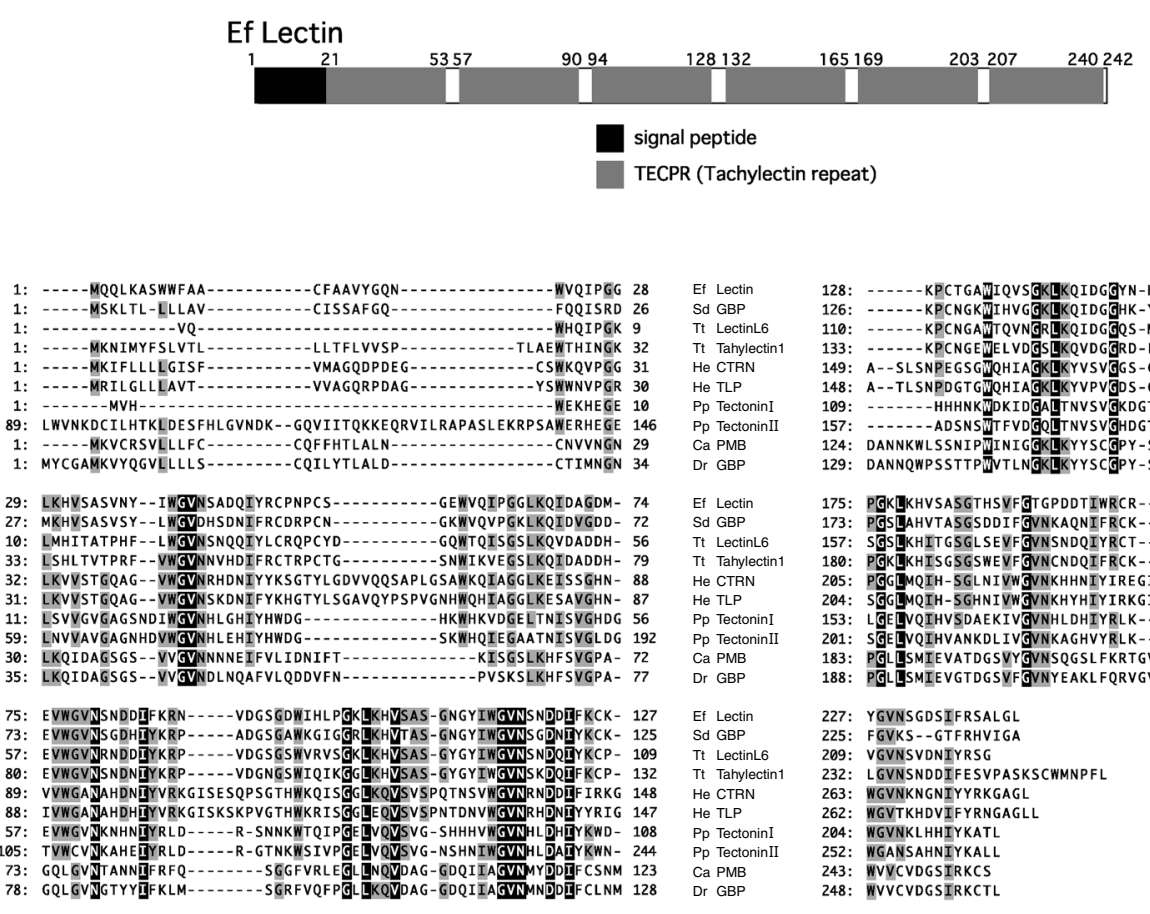

Ef Lectin
Sd GBP
Tt LectinL6
Tt Tahylectin1
He CTRN
He TLP
Pp TectoninI
Pp TectoninII
Ca PMB
Dr GBP
Ef Lectin
Sd GBP
Tt LectinL6
Tt Tahylectin1
He CTRN
He TLP
Pp TectoninI
Pp TectoninII
Ca PMB
Dr GBP
Ef Lectin
Sd GBP
Tt LectinL6
Tt Tahylectin1
He CTRN
He TLP
Pp TectoninI
Pp TectoninII
Ca PMB
Dr GBP

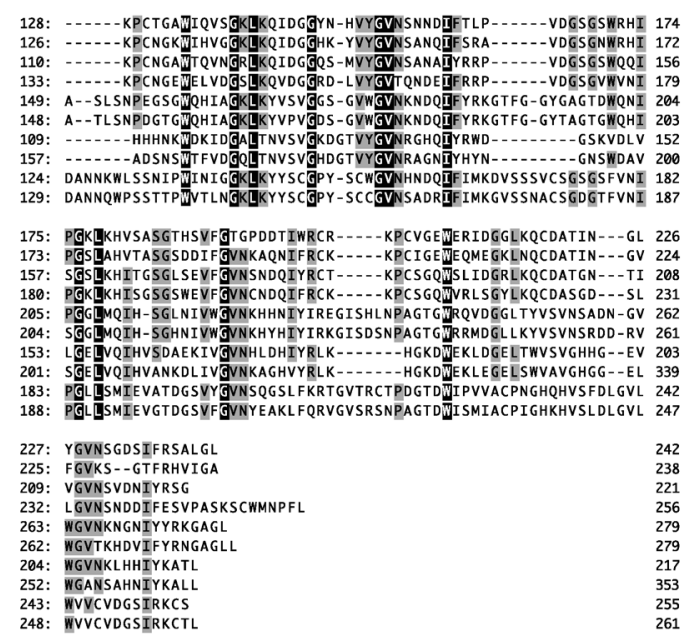

C

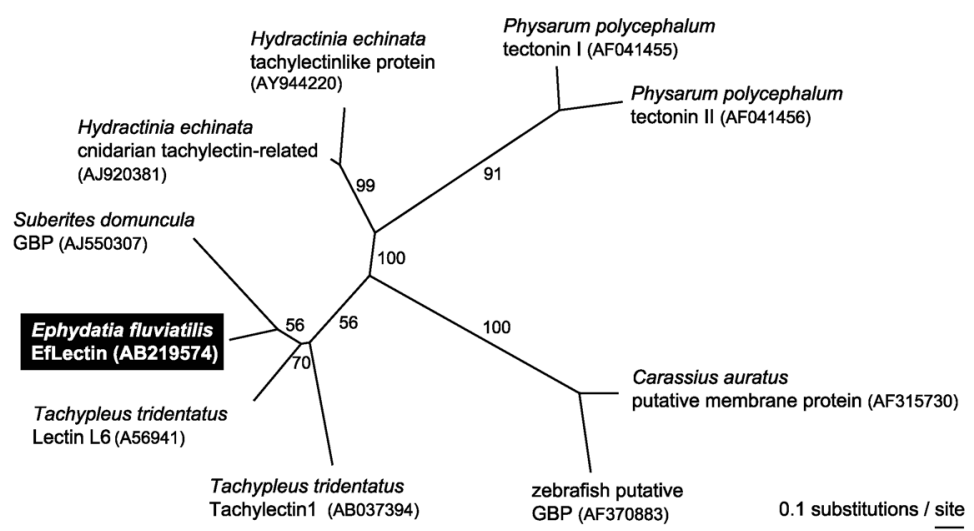

Fig. 4. Amino acid sequence of Ef lectin. (A) Schematic drawing of the structure of the Ef lectin protein. Signal peptide sequence and 6 tachylectin repeats of Ef lectin are indicated in black and gray squares, respectively. (B) Deduced amino acid sequence of Ef lectin aligned with related proteins. Amino acids that match perfectly in all proteins are highlighted in black; amino acids that match more than $51 \%$ are highlighted in gray. (C) Molecular phylogenetic unrooted tree of lectin-related genes. The tree was inferred by the neighbor-joining method using 121 amino acid residues, as described in Materials and Methods. Bootstrap values were calculated with 100 replicates. Accession numbers for the entries found in GenBank (PIR only for T. tridentatus lectinL6) are indicated in parentheses. An identical tree topology was obtained by the maximum-likelihood method. Note that we use two accession sequences of tachylectin1, tachylectin1(AB037394) and lectinL6 (A56941). Although tachylectin 1 and lectinL6 are the same gene, the amino acid sequence of lectinL6 was determined by peptide sequencing of the purified protein, whereas tachylectin was deduced from a cDNA sequence.

\section{Ef lectin expression during hatching from the gemmule}

In situ hybridization was performed with Ef_g5W_225J19 to analyze Ef lectin expression at various stages of germination. Ef lectin expression could not be detected in stage 2 (4-day) sponges (Figs. 5A, B). Ef lectin expression was detected in stage 4 (7-day sponge; Figs. $5 \mathrm{C}, \mathrm{D}$ ) and stage 5 (10-day sponge; Figs. 5E, F) sponges. Ef lectin-expressing cells were observed to be relatively large (Figs. 5D, F), distributed throughout the sponge body, and tended to be localized beneath the epithelial cells (data not shown). Ef lectin-expressing cells were seen clearly in the peripheral region of the sponge body, where the epithelial envelope composed of basopinacocytes and exopinacocytes flattens, and where the space between exo- and baso-pinacocytes narrows markedly (Figs. 5C, E). mRNA of Ef lectin appeared to be localized in the cytoplasm, because signals of Ef lectin were often seen as dots (Figs. 5D, F, arrows). The expression pattern indicated that Ef lectin is expressed in differentiated cells, presumably acting in defense against invading bacteria. 

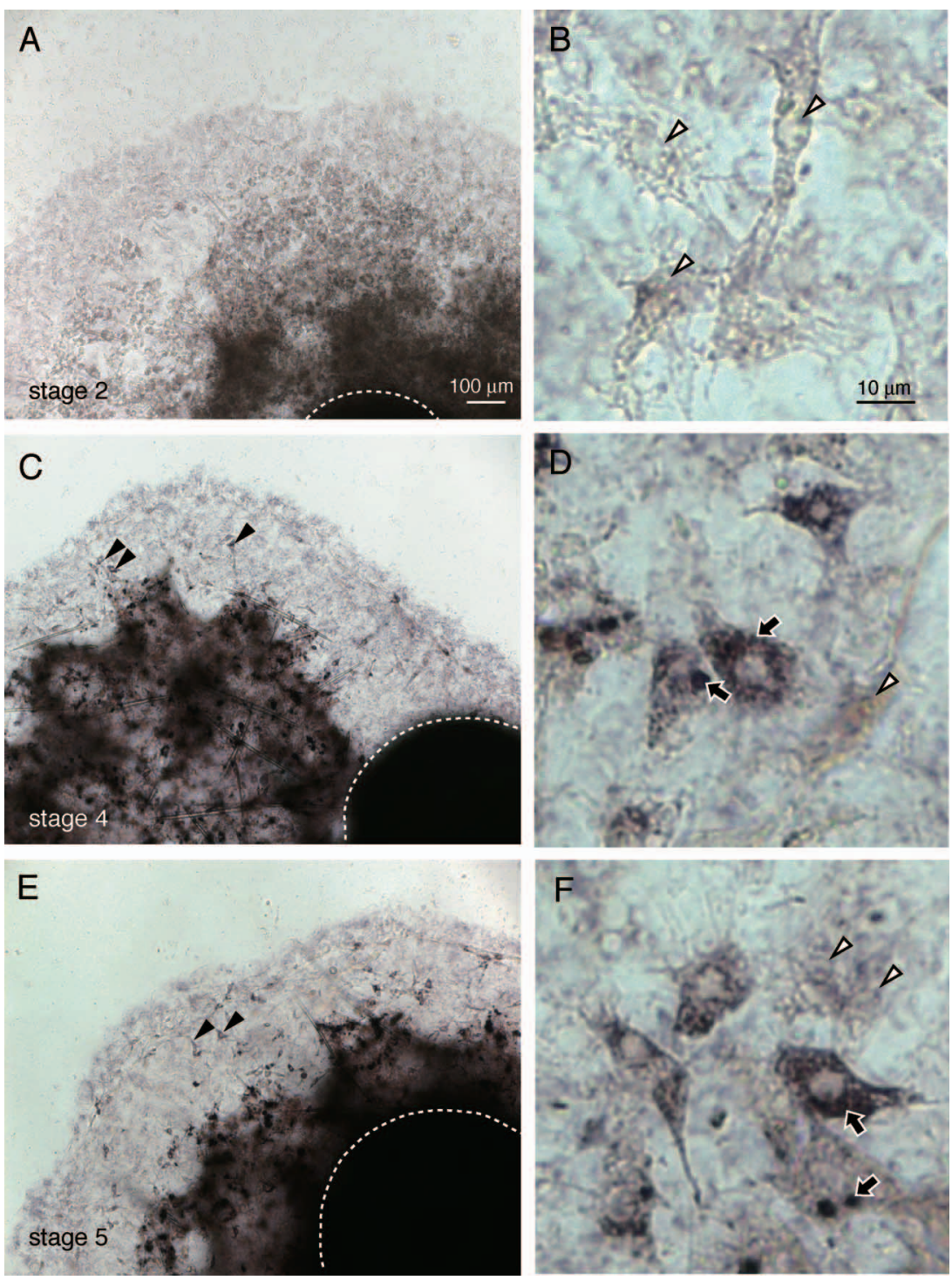

Fig. 5. Ef lectin expression during germination. Whole-mount in situ hybridization of Ef lectin at low magnification (A, C, E) and high magnification (B, D, F). Ef lectin is not expressed in stage 2 (A, white arrowheads in B). In stages 4 (C) and 5 (E), cells expressing Ef lectin were detected (black arrowheads). Ef lectin-positive cells are distributed throughout the sponge body (C, E), are relatively large in size, and have a flattened morphology with extensions (D, F). Ef lectin-negative cells in late developmental stages are indicated by white arrowheads (D, F). Examples of possible mRNA localization are suggested by dot signals (black arrows).

\section{Ef lectin protein expression during germination}

The expression pattern of Ef lectin protein was found to be similar to the mRNA expression pattern, as confirmed by western blot analysis (Fig. 6). For this analysis, we raised polyclonal antibodies ( $\mathrm{pAb}$ ) against a fusion protein corresponding to amino acid residues 21-160 of Ef lectin. Anti-Ef lectin $\mathrm{pAb}$ recognized protein bands corresponding to the approximately $16 \mathrm{KDa}$ purified fusion protein and the dimerized fusion protein at approximately $32 \mathrm{KDa}$ (Figs. 6A, lane 5 ; $6 \mathrm{~B}$, lane 4 ), but did not react with the negative-control fusion protein at about $28 \mathrm{KDa}$ (Figs. $6 \mathrm{~A}$, lane 6; 6B, lane 5). We analyzed sponges at stages 0,2 , and 4 , to cover the range of developmental stages (Fig. 1). Ef lectin protein was not detected in stages 0 (resting gemmule) and 2, but a 24
$\mathrm{KDa}$ Ef lectin protein band was specifically detected in stage 4 (Fig. 6B, lanes 1, 2 and 3, respectively). Western blot and in situ hybridization analyses clearly indicated that Ef lectin mRNA and protein are not expressed in early developmental stages (stages 0 and 2) of germination, but are expressed in late developmental stages (stages 4 and 5; Figs. 5, 6). This expression pattern also supports the idea that Ef lectin is expressed in either differentiating or differentiated cells. From these results, we conclude that Ef lectin can be used as a molecular marker for cells that may play a role in bacterial defense. 
A

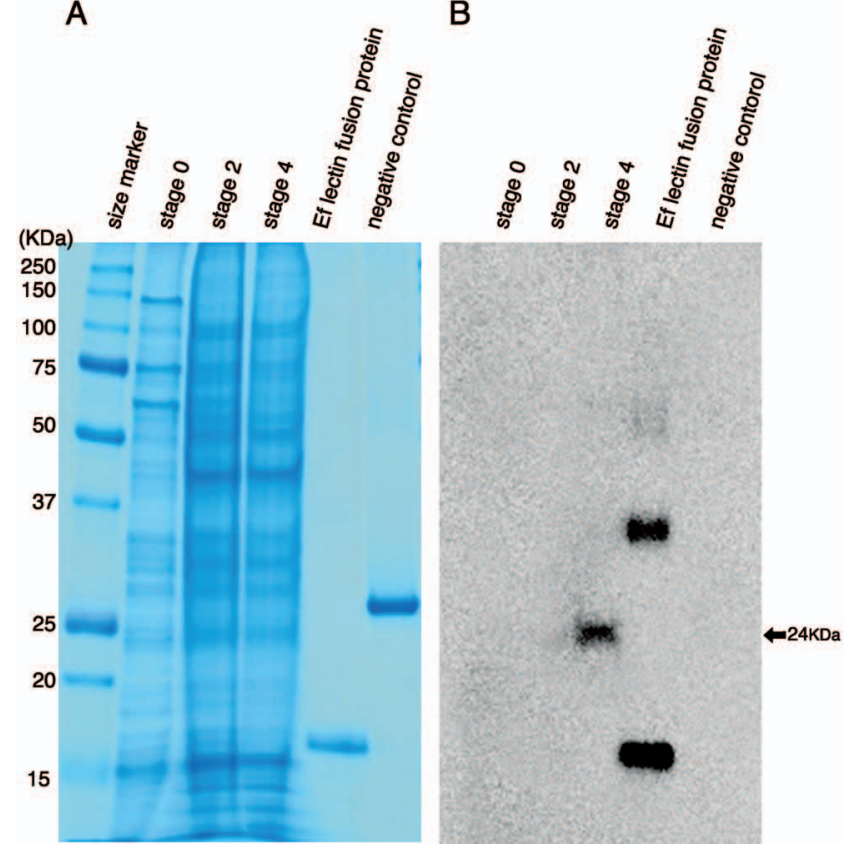

Fig. 6. Ef lectin protein expression during germination. Western blot analysis using anti-Ef lectin polyclonal antibodies (pAb). Blue staining of SDS-polyacrylamide gel electrophoresis (A) and corresponding western blot (B). $10 \mu \mathrm{g}$ of stage 0,2 , and 4 sponge total protein (lanes 1,2 , and 3 respectively), $0.1 \mu \mathrm{g}$ of Ef lectin fusion protein (lane 4) and $0.2 \mu \mathrm{g}$ of the negative-control fusion protein from EST clone Ef_g5w_034037N24 (lane 5). A 24 KDa protein band of endogenous Ef lectin was detected in mature sponges, stage 4 (B, lane 3 ) but not in the stage 0 resting gemmule or stage 2 sponges (B, lanes 1 and 2, respectively). A $16 \mathrm{KDa}$ Ef lectin fusion protein and its dimer were also detected (B, lane 4). Anti-Ef lectin pAb did not react with the $27 \mathrm{KDa}$ negative-control fusion protein.

\section{DISCUSSION}

\section{Ef silicatein as a molecular marker for sclerocytes}

We isolated Ef silicatein from our ongoing EST library as a candidate for a sclerocyte molecular marker. The Ef silicatein sequence is closely related to other known silicateins of marine sponges and to cathepsins from a wide range of animals. Three amino acids of the Ef silicatein catalytic site, $\mathrm{Ser}^{134}$ (Cys in cathepsin), $\mathrm{His}^{273}$ and $\mathrm{Asn}^{293}$, are conserved in the cathepsin family. The substitution of Cys to Ser in this site is characteristic of silicateins.

It is known that the sclerocyte first creates an axial filament consisting of protein, including silicatein. This filament lies inside an elongate vesicle and forms the basic substrate for silication. Using Ef silicatein as a probe for whole-mount in situ hybridization, sclerocytes that include a spicule in various developmental stages can be specifically detected (Fig. 3). The only non-spicule-containing cells that express Ef silicatein are the round cells, which tend to localize near the gemmule shell in the middle part of the sponge body at stage 2 (4-day sponge). For the following reasons, we speculate that this round cell is an archeocyte committed to the sclerocyte lineage, or a primary sclerocyte, that includes no spicule or only a very short one. In a previous study, we found that expression of a choanocyte lineage marker, Ef annexin, can be detected in possible archeocytes committed to differentiate into choanocytes in stage 2 (Funayama et al., 2005). Ef silicatein-expressing round cells also contain many yolk granules and show similar morphology to archeocytes committed to choanocytes. Recent studies in $S$. domuncula also suggest that archeocytes committed to sclerocytes express silicatein (Schröder et al., 2004). In addition, in stage 2 there are many archeocytes around the gemmule shell that should start differentiating. Since Ef silicatein was expressed in committed archeocytes and sclerocytes, we believe that Ef silicatein is a suitable sclerocyte lineage marker.

Recently, Schröder et al. (2005) found that the marine sponge $S$. domuncula silicatein beta gene is clustered in the genome with an ankyrin repeat-containing gene (SDANKrp), tumor necrosis factor receptor-associated factor (SDTNFRaf), and a protein kinase gene (SDPK), and that all of these genes are expressed in cells associated with spicules. These genes may be expressed in E. fluviatilis sclerocytes, and are good candidates for further sclerocyte markers. Unfortunately, we could not find these genes in our ongoing EST library in its current stage. By analyzing genes that are expressed in the process of spicule formation, we will be able to understand more about sclerocyte development.

\section{Ef lectin as a marker for the cell type involved in defense against invading bacteria}

Aquatic animals have to defend themselves against invading bacteria and viruses. Recently, a lectin called Sd GBP (previously called Lec SUBDO) was isolated from the marine sponge $S$. domuncula. It has binding capacity to LPS, and the purified protein has antibacterial activity (Schröder et al., 2003b). Sd GBP is related most to T. tridentatus tachylectin1/lectinL6, a novel type of lectin that also binds to bacterial LPS and inhibits bacterial growth. Although the biochemical characteristics of Sd GBP have beren well analyzed, the type of cell that expresses Sd GBP and its localization in the sponge body are unknown.

We isolated an $E$. fluviatilis lectin gene (Ef lectin) that encodes a lectin related to Sd GBP and tachylectin1/ lectinL6. The deduced amino acid sequence of Ef lectin has 6 tachylectin repeats, and a protein alignment and the unrooted phylogenetic tree showed Ef lectin to be closely related to both Sd GBP and tachylectin1/lectinL6 (Figs. 4B, C) Therefore, the function of Ef lectin is expected to be the same as the other lectins mentioned above, and Ef lectinexpressing cells would have a role in bacterial defense.

By in situ hybridization, we clarified that Ef lectin is not expressed at an early developmental stage, stage 2 (4-day sponge), but is expressed in late developmental stages 4 and 5 (7- and 10-day sponges, respectively) in relatively large cells (Fig. 5). This expression pattern and the putative function in defense against invading bacteria suggest that $E f$ lectin is expressed in the type of cell that acts in innate immunity. In other words, Ef lectin may be an appropriate 
marker for that cell type.

It has been reported that $S d$ GBP mRNA expression is induced by LPS in primmorphs (aggregates of dissociated cells) from cultured bacteria-free sponges (Schröder et al., 2003b). In contrast, even if we treat gemmules with $1 \%$ $\mathrm{H}_{2} \mathrm{O}_{2}$ to reduce bacterial and fungal contaminants, our system is not sterile and bacteria are still present, presumably coming from the gemmule itself. Therefore, during germination, as soon as cells which respond to innate immunity differentiate, exposure to bacteria would start Ef lectin expression. In our study, we have investigated the expression of $E f$ lectin caused by differentiation of the cells involved in innate immunity in late developmental stages of germination.

Our molecular phylogenetic analysis showed hydra tachylectin-related proteins (CTRN and TLP) to be in a different branch of an unrooted phylogenetic tree from Ef lectin, which groups with Sd GBP, tachylectin1, and lectinL6. This may reflect a functional difference between these two groups. CTRN is expressed in a subpopulation of neurons and their precursor cells, its expression is not induced by LPS treatment, and CTRN is proposed to have no function in innate immunity (Mali et al., 2005).

Tachylectins are composed of 5 types of hemocytederived lectins in Tachypleus tridentatus. Tachylectin1 is the only type of tachylectin that has no hemagglutinating activity, whereas tachylectins 2-5 have both LPS-binding and hemagglutinating activity. We could not find tachylectin types 2-5 in our EST library.

We attempted immunohistochemistry using anti-Ef lectin $p A b$ in various fixation conditions but could not get significant signal. Ef lectin is presumably a secreted protein making it difficult to detect in histochemical analyses, or the epitopes may be difficult to access after fixation.

\section{Molecular markers for the study of stem cell differentia- tion in sponges}

Recent studies using the marine sponge $S$. domuncula have revealed several new molecules involved in the defense against bacteria or fungi: LPS-interacting protein that binds to bacterial endotoxin LPS; MyD88, a perforin-like molecule functioning in defense against gram-negative bacteria (Wiens et al., 2005); lysozyme acting against grampositive bacteria (Thakur et al., 2005); and a receptor for (1, 3)-beta-D-glucans and fibrinogen for defense against fungi (Perovic-Ottstadt et al., 2004). However, the development of the cells of the innate immune system from archeocytes still remains unsolved. The germination system of $E$. fluviatilis is an excellent system to investigate archeocyte differentiation at the cellular level for the following reasons: all of the cell types constructing the sponge body directly or indirectly differentiate from archeocytes in the gemmule shell, and the extracellular matrix and spicules are still poorly developed during germination, making it easier to perform whole-mount in situ hybridization. The isolation of molecular markers for the stem cell, the archeocyte, is a primary task in order for us to investigate archeocyte differentiation into specialized cell types.

In this study, we have isolated molecular markers for two cell types: Ef silicatein as a sclerocyte lineage marker and Ef lectin as a marker for the cell type involved in defense against invading bacteria. In a previous study, we isolated a choanocyte lineage marker, Ef annexin. In situ hybridization of these cell-type-specific markers and archeocyte markers at various stages during germination will enable us to investigate archeocyte differentiation in molecular terms, further elucidating developmental mechanisms in sponges, the oldest group of metazoans.

\section{ACKNOWLEDGMENTS}

We greatly thank Dr. Yoko Watanabe for offering much help and guidance concerning sponges. We also thank Dr. Kurato Mohri for valuable discussion; Osamu Nishimura, Yukako Hirao, and Dr. Hiroshi Tarui for sequencing and constructing the EST database; and Jeremy Pulvers for careful reading of the manuscript.

This work was supported in part by a Grant-in-Aid for Exploratory Research to N. F., a Grant-in-Aid for Scientific Research on Priority Areas to K. A., a Grant-in-Aid for Creative Scientific Research to K. A. (17GS0318), and the Grant for the Biodiversity Research of the 21st Century COE (A14).

\section{REFERENCES}

Altschul SF, Madden TL, Schaffer AA, Zhang J, Zhang Z, Miller W, Lipman DJ (1997) Gapped BLAST and PSI-BLAST: a new generation of protein database search programs. Nucleic Acids Res 25: 3389-3402

Brien PM (1932) Contribution a l'etude de la regeneration naturelle chez les spongillidae. Spongilla lacustris (L.), Ephydatia fluviatilis (L.). Arch Zool Exp Gen 74: 461-506

De Sutter D, Van de Vyver G (1977) Aggregative properties of different Cell Types of the Fresh-Water Sponge Ephydatia fluviatilis isolated on ficoll gradients. Roux's Arch Dev Biol 183: 151161

Felsenstein $\mathrm{J}$ (1981) Evolutionary trees from DNA sequences: a maximum likelihood approach. J Mol Evol 17: 368-376

Funayama N, Nakatsukasa M, Hayashi T, Agata K (2005) Isolation of the choanocyte in the fresh water sponge, Ephydatia fluviatilis and its lineage marker, Ef annexin. Dev Growth Differ 47: 243-253

Huh CG, Aldrich J, Mottahedeh J, Kwon H, Johnson C, Marsh R (1998) Cloning and characterization of Physarum polycephalum tectonins. Homologues of Limulus lectin L-6. J Biol Chem 273: 6565-6574

Höhr D (1977) Differenzierungavorgange in der keimenden gemmula von Ephydatia fluviatilis. Roux's Arch Dev Biol 182: 329 346

Imsiecke G, Muller WE (1995) Unusual presence and intranuclear storage of silica crystals in the freshwater sponges Ephydatia muelleri and Spongilla lacustris (Porifera: Spongillidae). Cell Mol Biol (Noisy-le-grand) 41: 827-832

Katoh K, Misawa K, Kuma K, Miyata T (2002) MAFFT: a novel method for rapid multiple sequence alignment based on fast Fourier transform. Nucleic Acids Res 30: 3059-3066

Kawabata S, Iwanaga S (1999) Role of lectins in the innate immunity of horseshoe crab. Dev Comp Immunol 23: 391-400

Krasko A, Lorenz B, Batel R, Schroder HC, Muller IM, Muller WE (2000) Expression of silicatein and collagen genes in the marine sponge Suberites domuncula is controlled by silicate 
and myotrophin. Eur J Biochem 267: 4878-4887

Mali B, Soza-Ried J, Frohme M, Frank U (2005) Structural but not functional conservation of an immune molecule: a tachylectinlike gene in Hydractinia. Dev Comp Immunol 2005 Jun 20; [Epub ahead of print] http://dx.doi.org/doi:10.1016/j.dci.2005.04.004

Perovic-Ottstadt S, Adell T, Proksch P, Wiens M, Korzhev M, Gamulin V, Muller IM, Muller WE (2004) A (1 $\rightarrow 3$ )-beta-D-glucan recognition protein from the sponge Suberites domuncula. Mediated activation of fibrinogen-like protein and epidermal growth factor gene expression. Eur J Biochem 271: 1924-1937

Saito T, Kawabata S, Hirata M, Iwanaga S (1995) A novel type of limulus lectin-L6. Purification, primary structure, and antibacterial activity. J Biol Chem 270: 14493-14499

Saitou N, Nei M (1987) The neighbor-joining method: a new method for reconstructing phylogenetic trees. Mol Biol Evol 4: 406-425

Schröder HC, Krasko A, Le Pennec G, Adell T, Wiens M, Hassanein $\mathrm{H}$, Muller IM, Muller WE (2003a) Silicase, an enzyme which degrades biogenous amorphous silica: contribution to the metabolism of silica deposition in the demosponge Suberites domuncula. Prog Mol Subcell Biol 33: 249-268

Schröder HC, Ushijima H, Krasko A, Gamulin V, Thakur NL, DiehlSeifert B, Muller IM, Muller WE (2003b) Emergence and disappearance of an immune molecule, an antimicrobial lectin, in basal metazoa. A tachylectin-related protein in the sponge Suberites domuncula. J Biol Chem 278: 32810-32817

Schröder HC, Perovic-Ottstadt S, Wiens M, Batel R, Muller IM, Muller WE (2004) Differentiation capacity of epithelial cells in the sponge Suberites domuncula. Cell Tissue Res 316: 271280

Schröder HC, Perovic-Ottstadt S, Grebenjuk VA, Engel S, Muller IM, Muller WE (2005) Biosilica formation in spicules of the sponge Suberites domuncula: synchronous expression of a gene cluster. Genomics 85: 666-678
Shigenaga T, Takayenoki Y, Kawasaki S, Seki N, Muta T, Toh Y, Ito A, Iwanaga S (1993) Separation of large and small granules from horseshoe crab (Tachypleus tridentatus) hemocytes and characterization of their components. J Biochem (Tokyo) 114: 307-316

Shimizu K, Cha J, Stucky GD, Morse DE (1998) Silicatein alpha: cathepsin L-like protein in sponge biosilica. Proc Natl Acad Sci USA 95: 6234-6238

Simpson TL (1984) The Cell Biology of Sponges. Springer-Verlag, New York

Thakur AN, Thakur NL, Indap MM, Pandit RA, Datar VV, Muller WE (2005) Antiangiogenic, antimicrobial, and cytotoxic potential of sponge-associated bacteria. Mar Biotechnol (NY) 7: 245-252

Towbin H, Staehelin T, Gordon J (1979) Electrophoretic transfer of proteins from polyacrylamide gels to nitrocellulose sheets: procedure and some applications. Proc Natl Acad Sci USA 76: 4350-4354

Weissenfels N, Landschoff HW (1977) Bau und Function des Susswasserschwamms Ephydatia fluviatilis L.(Porifera) IV. Die Entwicklung der monazialen $\mathrm{SiO}_{2}$-Nadeln in Sandwich-Kulturen. Zool Jb Anat Bd 98: S355-S371

Wiens M, Korzhev M, Krasko A, Thakur NL, Perovic-Ottstadt S, Breter HJ, Ushijima H, Diehl-Seifert B, Muller IM, Muller WE (2005) Innate immune defense of the sponge Suberites domuncula against bacteria involves a MyD88-dependent signaling pathway:Induction of a perforin-like molecule. J Biol Chem 280: 27949-27959

Yang Z (1994) Maximum likelihood phylogenetic estimation from DNA sequences with variable rates over sites: approximate methods. J Mol Evol 39: 306-314

Yang Z (1997) PAML: a program package for phylogenetic analysis by maximum likelihood. Comput Appl Biosci 13: 555-556

(Received July 5, 2005 / Accepted August 2, 2005) 